Role of agricultural engineering in environmental and sustainable development

for the valley and delta areas: 1259 - 1287

\title{
COMPARATIVE PERFORMANCE OF SOLAR TUNNEL GREENHOUSE AND OPEN SUN DRIING SYSTEMS DURING SEEDLESS GRAPE DRYING
}

\author{
ABDELLATIF, S. M ; MOHMED, A. T. ; AND MOSAD, G. A.*
}

\section{ABSTRACT}

Drying is simply the process of moisture removal from an agricultural product, and can be performed by different methods. The main purpose of this research work was to study the thermal performance of two different solar driers (active and passive dryers) based on the energy balance equations for the drying air and the drying product during dehydration process of seedless grapes in August 2009 under the climatic conditions of El-Mansoura city $\left(31.05^{\circ} \mathrm{N}\right.$ and $\left.31.37^{\circ} \mathrm{E}\right)$, Egypt. Three identical solar tunnel greenhouse driers (STGD) were functioned as an active solar drier, and an open sun drier (OSD) under direct solar radiation without cover (as a passive solar drier) to dry seedless grapes. The three active solar driers were operated under three different mass flow rates of $0.122,0.183$, and $0.259 \mathrm{~kg} / \mathrm{s}$. Three different shapes of grapes (clusters, parts, and grains) with total quantity of $33 \mathrm{~kg}$, were spread on wire mesh tray with floor surface area of $2.0 \mathrm{~m}^{2}$. The results of greenhouse solar driers were compared individually with open sun drying. During the drying process, it was observed that, the hourly average air drying temperatures inside the three active solar dryers were increased to $49.9,45.5$, and $40.1^{\circ} \mathrm{C}$, respectively, whereas the hourly average ambient air temperature was $31.6^{\circ} \mathrm{C}$. The seedless grapes could be dried from initial moisture content of $79.1 \% \mathrm{wb}$ to $17.1,18.5$, and $20.8 \% \mathrm{wb}$ within drying time of 61, 61, and $71 \mathrm{hrs}$, using the three active solar dryers, respectively, while it was taken 96 hrs under open sun drying method to reach the final moisture content of $21.2 \% \mathrm{wb}$. The daily average thermal efficiencies for the four different solar drying modes, respectively, were $22.37 \%, 21.57 \%, 19.12 \%$, land $10.81 \%$. The quality of raisin (dried grapes) in terms of physicochemical parameters such as colour retention and water activity were evaluated.

*Dept. of Agricultural Engineering, Faculty of Agric. Mansoura University 
The overall study concluded that good quality dehydrated raisin could be produced by using active solar dryers as compared with passive sun drying method. The produced raisin of grapes under different drying methods had various colours. They, respectively, were light brown and dark brown when the grapes dried under active solar dryers and passive sun drying method. The experimental work showed that, the solar tunnel greenhouse drying (active solar dryer) was satisfactory and competitive to a natural convection solar drying process (passive dryer).

Keywords: open sun drying; solar tunnel greenhouse drier; seedless grapes.

\section{INTRODUCTION}

7 he drying process is a heat and mass transfer phenomenon where water migrates from the interior of the drying product onto the

surface from which it evaporates. Heat is transferred from the surrounding air to the surface of the product. A part of this heat is transferred to the interior of the product, causing in rising of both temperature and vapour pressure, and formation of water vapour and the remaining amount is utilized in evaporation of the moisture from the surface. The moisture from the interior transfers to the surface in order to replace the loss of moisture occurred by evaporation. In the initial stages, the moisture removal is rapid since the excess moisture on the surface of products presents a wet surface to the drying air (constant rate). After a certain amount of water has been evaporated from the products, the drying rate slows down. The evaporation rate is reduced, and the temperature of the products tends to rise (falling rate of drying). The removal of water from the surface requires an amount of heat energy equal to the latent heat of vaporization of water and a current of air moving past the surface to carry away the water vapour. The equilibrium moisture content is used to determine if a product will gain or loss moisture under a given set of temperature and relative conditions (EIGhetany, 2006).

Egypt as a developing country and its geographical location has a great amount of natural energy such as solar energy. Heated air by solar energy can be utilized for either heating or drying different agricultural products. Therefore using solar energy can considerably reduce the energy costs 
(Abdellatif and Helmy, 1993). The efficiency of a solar dryer depends on its type and model as well as on the rate of heat loss during operating (Timoumi et al., 2004). One of the great important potential applications of solar energy is solar drying of agricultural products (grapes, apricots, bananas, tomatoes, green peas, and green beans). Losses of agricultural product in developing countries are estimated in the range of 30-40\% of total production (Jayaraman and Gupta, 1995). Solar dryers can generally be classified into two broad categories depending upon the mode of heating or the mode of their operation; active and passive solar dryers. Passive dryers use only the natural movement of heated air. They can be constructed easily with inexpensive, locally available materials such as wood is readily available (El-Sebaii et al., 2002a). Passive drying is a well-known food preservation technique that reduces the moisture contents of agricultural products, and prevents deterioration within a period of time regarded as the safe storage period. Considerable losses occur during this drying process because of influences such as birds, insects, rodents, rain, and microorganisms. The quality of dried product can be seriously degraded so it sometimes becomes inedible. To overcome these problems, an active solar dryer is commonly used. Active solar dryers are designed incorporating external means, such as fans or pumps, for moving the solar energy in the form of heated air from the collector area to the drying beds. An advanced and alternative method to the traditional techniques is greenhouse drying in which the product is placed in trays receiving solar radiation through the plastic cover, while moisture is removed by natural convection or forced air flow (Condori and Luis, 1998 ; Kumar and Tiwari, 2007). This double function, greenhouse and dryer, improves the rate of the initial investment (Condori et al., 2001), thus maintaining the good quality, increasing the storage capacity and reducing the wastage of the crop simultaneously (Tiwari, 2003).

The grapes are in equilibrium with their surrounding conditions of temperature and relative humidity when the vapour pressure of the surrounding air are equal to the vapour pressure corresponding to the saturation temperatures of water inside the grapes. The relative humidity of the surrounding air during equilibrium is known as the equilibrium 
relative humidity at a particular temperature. The latent heat of vaporization of grapes appears to be a function of the equilibrium moisture content (Matteo et al., 2000). Yaldiz et al. (2001) investigated a thin layer solar drying of sultana grapes. They reported that the solar drying process of grapes occurred in the falling rate period. They presented a two term drying model and compared it with eight different thin layer drying models. Matteo et al. (2000) stated that grape drying to produce raisins is a very slow process due to the peculiar structure of the grape peel, which is mainly covered by a waxy layer. Removal of the waxy layer from the grape peel by abrasion was found to be as effective as the traditional chemical dipping method, and hence, the drying time of pretreated grapes is up to four times shorter than the drying time of untreated grapes. An indirect type natural convection solar dryer was experimentally and theoretically investigated for drying grapes (ElSebaii et al., 2002a). They found that, the drying constant obtained from the experimental results correlated with the temperature of the drying product. El-Sebaii et al., 2002b found that, the equilibrium moisture content for seedless grapes is reached after 60 and $72 \mathrm{hrs}$ when the system is used with and without storage material, respectively. They also found that, the heat storage medium and chemical pretreatment have caused significant decreases of the drying time of the seedless grapes. The effects of initial and final moisture contents, drying air temperature, relative humidity, and velocity of air drying on the drying constants have been investigated by several researchers (Tiwari et al., 1997 ; Ayensu, 1997 ; Pangavhane et al., 1999 ; Kumar and Tiwari, 2006 , and ElSahrigi, et al., 2007). Although the data in the literature are found to be different due to both differences in experimental procedures and the theoretical methodologies used, the behaviour of the grapes during drying process has been subject of various researches.

The main goals of this research work are to utilize both active and passive solar dryers for drying seedless grapes during August of 2009. The objectives of this study are to verify experimentally the drying characteristics of thin layer of grapes through studying the drying behaviour, computing the equilibrium moisture content with specific conditions of the drying air temperature and relative humidity and, 
finally, to compare experimentally between the active and passive solar drying methods.

\section{MATERIALS AND METHODS}

\subsection{Experimental set-up and procedure}

Three similar tunnel greenhouses are constructed and installed on the roof of the agricultural engineering department at Mansoura University (latitude and longitude angles, respectively, are $31.045^{\circ} \mathrm{N}$ and $31.37{ }^{\circ} \mathrm{E}$ ) as shown in Fig. (1). Each one having an outer gross dimensions of 2.02 $\mathrm{m}$ long, $1.06 \mathrm{~m}$ wide, and 0.5 high with a net drying surface area of 2.0 $\mathrm{m}^{2}$ and $0.710 \mathrm{~m}^{3}$ internal volume of drying chamber. The experimental set-up apparatus is constructed to study the drying characteristics of thin layer drying system of seedless grapes. Each solar tunnel was covered with single layer of polyethylene sheet $200 \mu$ thick. Three different sizes of seedless grapes (cluster, parts, and grains in tunnels 1, 2, and 3, respectively) were uniformly spread on wire mesh box having gross dimensions of $2.0 \times 1.0 \mathrm{~m}$. Each tunnel is equipped with a blower driven by a $0.5 \mathrm{hp}$ electric motor at $3000 \mathrm{rpm}$, and $220 \mathrm{~V}$. It was controlled by vertical gate to provide the desired level of mass flow rate required for drying seedless grapes. Drying air was cycled through the tunnel which continuously had a hot air heated by solar energy. After mixing with the hot air inside the tunnel, the heated air penetrated the grapes in the dryer box. Therefore, the drying air was continuously introduced from the top and leaves through the bottom as revealed in Fig. (2).Three different volumetric flow rates of air drying; 5.94, 9.00 and $12.82 \mathrm{~m}^{3} / \mathrm{min}$ were used for solar driers 1, 2 and 3, respectively, during the experimental work. These volumetric flow rates, respectively, were provided the mass flow rates of $0.122,0.183$, and $0.259 \mathrm{~kg} / \mathrm{s}$. A wooden drying box having a gross dimensions of $2.0 \mathrm{~m}$ long, $1.0 \mathrm{~m}$ wide, and $0.1 \mathrm{~m}$ high was located on a movable iron frame having a height of $0.35 \mathrm{~m}$. It was situated beside the solar tunnel greenhouse in order to use as an open sun drying system without any cover. This drying box was divided into three equal parts, the first one for the cluster drying, the second for the parts, and the last one for the grains drying. The seedless grapes were bought from the market and checked up carefully to discard spoiled ones in order to prevent contamination of grapes by bacteria or fungi. 


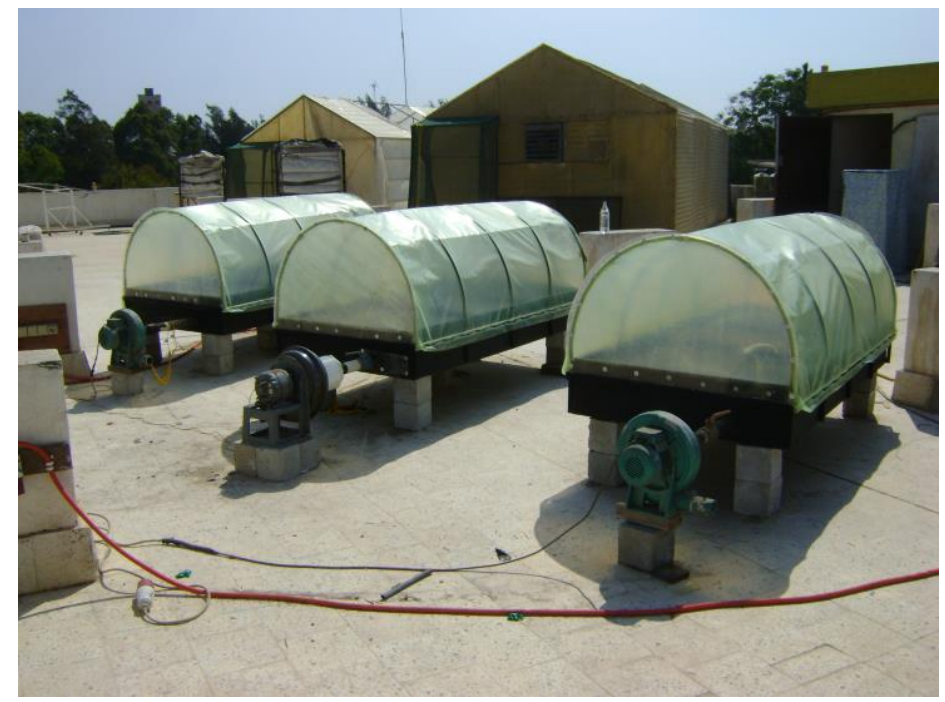

Fig. (1): Solar tunnel greenhouses (Quonset type) using as an active solar dryers during the experimental period.

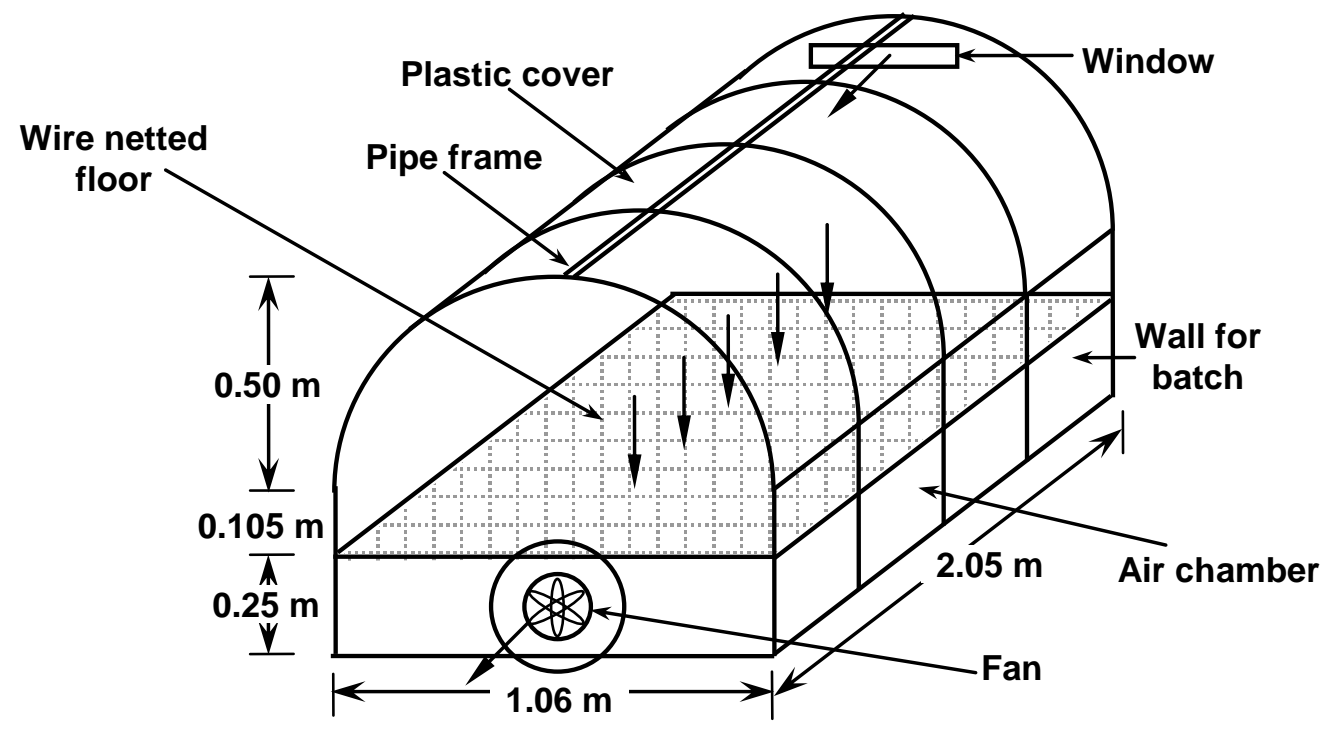

Fig. (2): schematic diagram of the active and passive solar dryers. 
For ensuring uniformity of the physical properties of the dried grapes, the berries for each solar and sun drying systems are selected as the same size. The fresh seedless grapes were washed with tape water to remove the dust and dirt. Pretreatment was made before drying process, for each solar and sun dryers, $33 \mathrm{~kg}$ (capacity of each dryer) of grapes were blanched by dipping in boiling solution of $1 \%$ hydroxide sodium $(\mathrm{NaOH})$ solution at $90 \mathrm{oC}$ for 10 seconds of $1 \mathrm{~kg}$ of grapes and immediately washed by immersing in cold water. After that the grapes immersed in $1 \%$ sodium metabisulfite solution for 5 minutes, then washed with pure water to be alkaline free (Ibrahim, 1990). The main objective of this chemical process was to create cracks in the surface of the waxy peel for increasing drying rate and giving a yellowish shiny color of the raisin. In this study, the moisture content of grapes was determined according to the method recommended by (AOAC, 1995). Drying experiment was carried out under active passive solar dryers from the beginning of August 2009.

\subsection{Instruments and data acquisition}

The meteorological data included solar radiation flux incident on a horizontal surface (pyranometer), dry-bulb air temperature (shelted and vented thermistor), wind speed and its direction (cup anemometer and wind van), and air relative (hygrometer) were obtained from the meteorological station (WatchDog, model 550, USA) which installed 3.0 $\mathrm{m}$ above the solar dryers. To measure the solar radiation flux incident on a horizontal surface inside the solar dryer, another pyranometer was situated inside the first tunnel and connected with the meteorological station. The data were displayed on the video screen and updated by a scan of all the sensors every one minute. The mean of 15 scans was recorded on a hard-disk every 15 minutes using a data logging program (space ware 6.02). A 12 channels data-logger (Digi-Sense Scanning Thermometer Type, USA) was also used for taking and storing reading from different sensors (Thermocouples, K-type with an accuracy of \pm $0.2^{\circ} \mathrm{C}$ ). Each solar tunnel dryer (active solar dryer) was instrumented with four thermocouples for measuring dry-bulb air temperatures at different locations (on the middle of the tunnel $0.25 \mathrm{~m}$ above the grapes, the grapes temperature, air temperature in the drying chamber, and exhaust 
air). The air relative humidity and air speed of the exhaust air were measured using hot wire anemometer. Infrared thermometer (Raytek, Rayner ST60, USA) was also used to measure the temperature of the cover material (polyethylene sheet). The time interval for data recording was 15 minutes with data acquisition every one minute for integrated measurements.

\subsection{Mathematical modeling}

The three greenhouse type dryers operated under quasi steady-state conditions as an air heating solar collectors. In these circumstances, the thermal performance of a greenhouse type dryer is described by an energy balance that indicates the distribution of the solar energy available $(\mathrm{Q})$ into useful energy gain $\left(\mathrm{Q}_{\mathrm{c}}\right)$, rate of heat energy utilized to evaporate moisture from the grapes $\left(\mathrm{Q}_{\mathrm{ev}}\right)$, and thermal losses $\left(\mathrm{Q}_{\text {loss }}\right)$, (Duffie and Beckman, 1991 ; Bargach, et al., 2000 ; ASHRAE, 2005). The heat energy balance can be computed as follows:-

$$
\mathbf{Q}=\mathbf{Q}_{\mathbf{u}}+\mathbf{Q}_{\mathrm{ev}}+\mathbf{Q}_{\text {loss }}, \quad \text { Watt }
$$

The useful heat gain by a drier can be expressed as:

$$
\mathbf{Q}_{\mathbf{u}}=\mathbf{m}_{\mathbf{a}} \mathbf{C}_{\mathbf{P}}\left(\mathbf{T}_{\mathbf{a i}}-\mathbf{T}_{\mathbf{a} 0}\right), \quad \text { Watt }
$$

Where, $\mathrm{m}_{\mathrm{a}}$, and, $\mathrm{C}_{\mathrm{P}}$, respectively, are the flow rate of air $\left(\mathrm{kg} \mathrm{s}^{-1}\right)$, and the specific heat of air $\left(\mathrm{J} \mathrm{kg}^{-1}{ }^{\circ} \mathrm{C}^{-1}\right), \mathrm{T}_{\mathrm{ai}}$, is the air temperatures inside the solar drier $\left({ }^{\circ} \mathrm{C}\right)$, and $\mathrm{T}_{\mathrm{ao}}$, is the outside air temperature $\left({ }^{\circ} \mathrm{C}\right)$. The total thermal energy utilized for drying grapes includes; the sensible heat used to raise the temperature of grapes $\left(\mathrm{Q}_{\mathrm{S}}\right)$, and the latent heat energy used to vaporize the water in the grapes $\left(\mathrm{Q}_{\mathrm{L}}\right)$, it can be calculated as follows:-

$$
\begin{aligned}
& \mathbf{Q}_{\mathrm{ev}}=\mathbf{q}_{\text {Latent }}+\mathbf{q}_{\text {Sensible }}, \quad \text { Watt }
\end{aligned}
$$

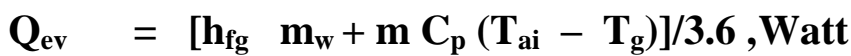

Where, $\mathrm{T}_{\mathrm{g}}$, is the grape temperature $\left({ }^{\circ} \mathrm{C}\right)$ and, $\mathrm{h}_{\mathrm{fg}}$, is the latent heat of vaporization of grapes ( $\left.\mathrm{kJ} \mathrm{kg}^{-1}\right)$, it can be computed as follows(Gallaher, 1951):-

$$
\mathbf{h}_{\mathrm{fg}}=2393.673\left(1+23 \mathrm{e}^{-0.40 \mathrm{M}(\mathrm{d} . \mathrm{b} . \%)}\right), \quad \quad \mathrm{kJ} \mathrm{kg}^{-1}
$$

$\mathrm{m}_{\mathrm{w}}$, is the mass of water evaporated from the drying grapes during the process over any time period $\left(\mathrm{kg} \mathrm{hr}^{-1}\right), \mathrm{m}$, is the mass of grapes in the drier, $\mathrm{C}_{\mathrm{p}}$, is the specific heat of grapes, it can estimated as(Dickerson, 1969):-

$$
\mathrm{C}_{\mathrm{p}}=1.672+0.025 \mathrm{M}(\mathbf{w . b . \%}), \quad \mathrm{kJ} \mathrm{kg}^{-1}{ }^{\mathrm{o}} \mathrm{C}^{-1}
$$


Where, $\mathrm{M}$, is the moisture content of grapes at interval time in weight bases. The thermal losses from the inside solar dryers into the outside can be computed as follows:-

$$
\mathbf{Q}_{\text {loss }}=\mathbf{U}_{\mathbf{o}} \mathbf{A}_{\mathbf{c}}\left(\mathbf{T}_{\mathrm{ai}}-\mathbf{T}_{\mathrm{ao}}\right), \quad \text { Watt }
$$

Where, $U_{o}$, is the overall heat transfer coefficient $\left(\mathrm{W} \mathrm{m}^{-2}{ }^{\circ} \mathrm{C}^{-1}\right), \mathrm{A}_{\mathfrak{c}}$, is the surface area of the polyethylene cover $\left(\mathrm{m}^{2}\right)$ and, $\mathrm{T}_{\mathrm{ao}}$, the outside air temperature.

The main characteristics, which used for performance estimation of any solar drying system, are the drying rates and the daily drying efficiency. The drying rate may be expressed as the thin layer drying equation:

$$
\frac{d M}{d t}=-k\left(M_{t}-M_{e}\right)
$$

Where, $\mathrm{k}$ and $\mathrm{M}_{\mathrm{e}}$, respectively, are the drying constant $\left(\mathrm{s}^{-1}\right)$ and the equilibrium moisture content $(\%), \mathrm{t}$, is the desired time period (s), and, $\mathrm{M}_{\mathrm{t}}$, is the instantaneous moisture content, which can be estimated as well as the final moisture content throughout the drying process. Various mathematical models have been proposed by several researchers describing the moisture movement in different agricultural products such as the exponential model, approximation of diffusion model, and Page equation model. Based on the presented thin layer models, the exponential model appears to the most suitable one describing the drying characteristics of the seedless grapes using solar drying systems. However, the moisture ratio $\mathrm{MR}=\mathrm{M} / \mathrm{M}_{\mathrm{o}}$ Newton model (Ayensu,1997) was taken in place of $M R=\left(M-M_{e}\right) /\left(M_{o}-M_{e}\right)$ for mathematical modeling of the solar drying curves due to the continuous fluctuation in the relative humidity of the drying air during solar drying process (Diamente and Munro, 1993).

$$
\text { MR }=\frac{M-M_{e}}{M o-M_{e}}=\exp (-k t)
$$

The daily drying efficiency $\left(\eta_{d}\right)$ is the ratio of energy required to evaporate the moisture from the grapes to the solar radiation flux incident received over the surface area of the drying box, given as:

$$
\boldsymbol{\eta}_{\mathbf{d}}=\frac{\mathbf{Q}_{\mathrm{ev}}}{\mathbf{R} \mathbf{A}_{\mathbf{d}}} \times \mathbf{1 0 0}, \quad \%
$$

Data were measured and stored in a microcomputer files for computation and analysis. A computer model has been developed and used for 
computing the drying characteristics and efficiency during the experimental period using the previous equations. The developed mathematical model has been solved with the help of computer program based on MATLAB. The program requires two input files: one contains the simulation parameters and the other contains the input data. Table (1) lists all inputs required to run the program together with the parameter values used for the simulation runs. The simplified flowchart for MATLAB program is shown in Fig. (3).

Table (1): Parameters and variables required as input and variables output by MATLAB program.

\begin{tabular}{|l|c|}
\hline Configuration file input & Values \\
\hline Surface area of the drying box $\left(\mathrm{A}_{\mathrm{d}}\right), \mathrm{m}^{2}$ & 2.00 \\
\hline Surface area of the drying grapes $\left(\mathrm{A}_{\mathrm{dp}}\right), \mathrm{m}^{2}$ & 1.80 \\
\hline Surface area of the polyethylene cover $\left(\mathrm{A}_{\mathrm{c}}\right), \mathrm{m}^{2}$ & 4.47 \\
\hline Specific heat of the drying air $\left(\mathrm{C}_{\mathrm{p}}\right), \mathrm{J} \mathrm{kg}^{-1}{ }^{\circ} \mathrm{C}^{-1}$ & 1006.0 \\
\hline Effective absorption of the grape grains $(\alpha)$, decimal & 0.75 \\
\hline Initial weight of the grapes $\left(\mathrm{W}_{\mathrm{i}}\right) . \mathrm{kg}$ & 33.0 \\
\hline Initial moisture content on wet basis $\left(\mathrm{M}_{\mathrm{i}}\right), \%$ & 78.80 \\
\hline Overall heat transfer coefficient $\left(\mathrm{W} \mathrm{m}^{-2}{ }^{\circ} \mathrm{C}^{-1}\right)$ & 6.30 \\
\hline Data file inputs & \\
\hline Mass flow rate of the drying air $\left(\mathrm{m}_{\mathrm{a}}\right), \mathrm{kg}$ hr & -1 \\
\hline Temperature of the drying air $(\mathrm{Tai}),{ }^{\circ} \mathrm{C}$ & \\
\hline Temperature of the outside ambient air $\left(\mathrm{Tao}^{-1},{ }^{\circ} \mathrm{C}\right.$ & \\
\hline Temperature of the outside ambient air $\left(\mathrm{T}_{\mathrm{ao}}\right),{ }^{\circ} \mathrm{C}$ & \\
\hline Latent heat of vaporization of water $\left(\mathrm{h}_{\mathrm{fg}}\right), \mathrm{kJ} \mathrm{kg}$ & \\
\hline Solar radiation flux incident inside the dryer $(\mathrm{R}), \mathrm{W} \mathrm{m}{ }^{-2}$ & \\
\hline Final moisture content on wet basis $\left(\mathrm{M}_{\mathrm{f}}\right), \%$ & \\
\hline Equilibrium moisture content on wet basis $\left(\mathrm{M}_{\mathrm{e}}\right), \%$ & \\
\hline Instantaneous moisture content on wet basis $\left(\mathrm{M}_{\mathrm{t}}\right), \%$ & \\
\hline Data outputs & \\
\hline Useful heat gain by a solar dryer $\left(\mathrm{Q}_{\mathrm{c}}\right), \mathrm{Watt}$ & \\
\hline Mass of water evaporated from the drying grapes $\left(\mathrm{m}_{\mathrm{w}}\right), \mathrm{kg}$ & \\
\hline $\begin{array}{l}\text { Heat utilized to evaporate moisture from the grapes }\left(\mathrm{Q}_{\mathrm{ev}}\right), \\
\text { Watt }\end{array}$ & \\
\hline Thermal losses from the inside solar dryer, $\left(\mathrm{Q}_{\text {loss }}\right), \mathrm{Watt}$ & \\
\hline Drying constant $(\mathrm{k}), \mathrm{hr}{ }^{-1}$ & \\
\hline Drying efficiency of greenhouse type dryer $\left(\eta_{\mathrm{d}}\right), \%$ & \\
\hline
\end{tabular}




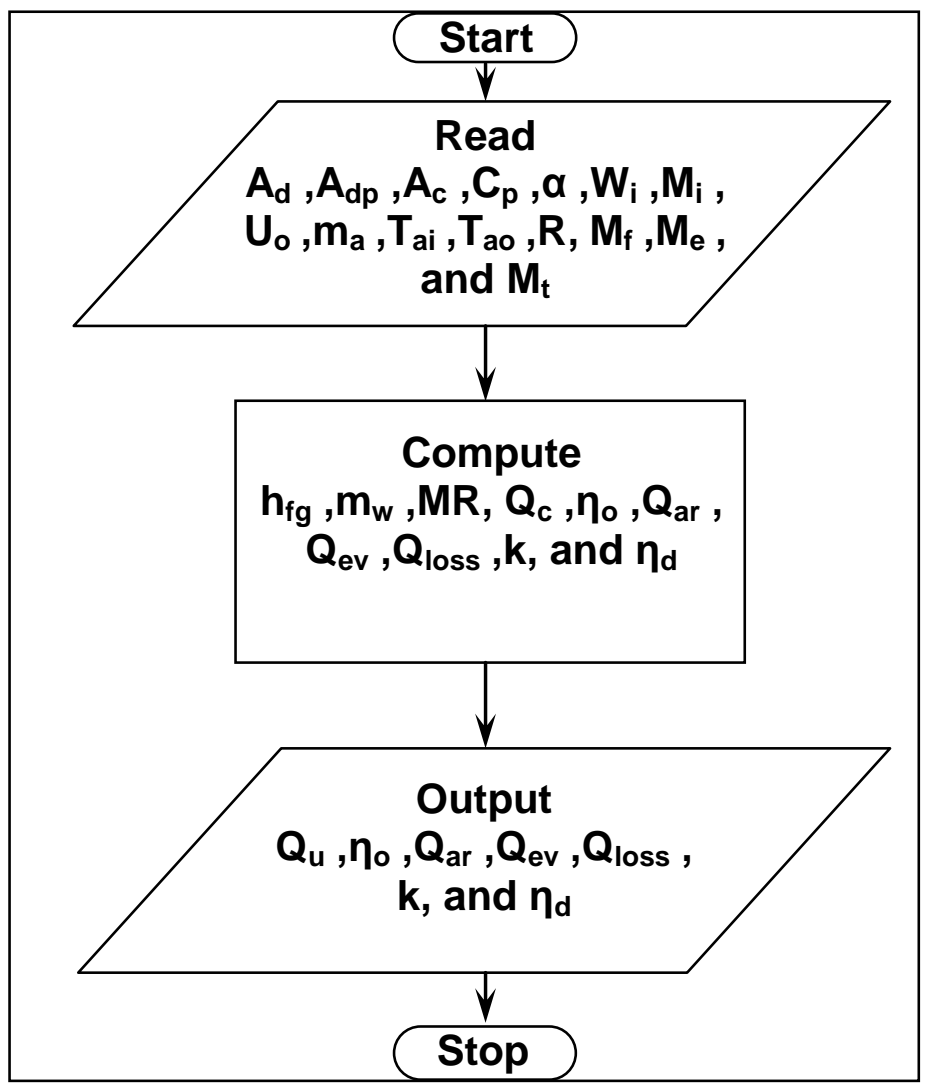

Fig. (3): Simplified flowchart for the developed MATLAB program.

\section{RESULTS AND DISCUSSION}

The main purpose of drying process is to reduce the moisture content of the agricultural product to a safe level to minimize the deterioration of the quality of product during storage. Drying rate of the agricultural product is controlled by the rate at which the product's internal moisture is released from its surface and the rate at which moist air is removed from the area surrounding the product.

During the experimental period, the four different solar driers (STGD1, STGD2, and STGD3), and open sun drying system (OSDS) were loaded by $33 \mathrm{~kg}$ of treated seedless grapes which divided into three equal amounts of different shapes (clusters, parts, and grains).The solar driers STGD1 and STGD2 were operated on 4/8/2009 at 11 am till 10/8/2009 at $4 \mathrm{pm}$ about 7 days, 61 hours). The solar drier STGD3 was operated on 
3/8/2009 at 10 am until 10/8/2009 at 4 pm (8 days, 71 hours). Whereas, the open sun drying system (OSDS) was operated on 4/8/2009 at 9 am until 14/8/2009 at 4 pm (11 days, 96 hours). The daily average solar energy available outside and inside the solar tunnel greenhouse driers and the drying parameters are summarized and listed in Table (2).

The hourly average drying air temperatures for the three solar driers (STGD 1, 2, and 3) and open sun drying were 53.5, 44.1, 41.0, and $31.6^{\circ} \mathrm{C}$, respectively, while the outside air temperature was $31.6^{\circ} \mathrm{C}$. Accordingly, the complied data showed that, the solar tunnel greenhouses drier increased the drying air temperatures by $21.9,12.5$, and $9.4^{\circ} \mathrm{C}$, respectively. These differences in drying air temperatures can be attributed to the different mass flow rates of air during the experimental period. As the mass flow rate of drying air passing through the solar tunnels is increased above the recommended rate of $0.005 \mathrm{~m}^{3} \mathrm{~m}^{-2} \mathrm{~s}^{-1}$ the drying air temperature is reduced, although the effect is not as pronounced at higher air flow rates. At constant mass flow rate of air drying (for each drier), the drying air temperature inside the solar driers had a strong effect on the grapes temperature. The variation in curves of the grapes temperature as a function of drying time for the three solar tunnel greenhouse driers is shown in Fig. (4). It can be observed a sinusoidal variation of the grapes temperature with drying time. It is also obvious from this figure that, the fluctuations in the drying air and grapes temperatures during the experimental period almost had the same trend inside the three solar driers. The grapes temperature in the solar driers and the open sun drying system varied from 25.3 to $55.7^{\circ} \mathrm{C}$. The diurnal variation amplitude under solar tunnel greenhouse driers was more significant. The maximum grape temperatures during the experimental period for the three solar driers reached to $63.3,51.5$, and $46.8^{\circ} \mathrm{C}$, respectively which occurred at and around noon. At nighttime the grape temperatures and the air temperatures inside the solar driers were almost fit with the outside air temperature. While, during the daylight the grape temperatures were usually greater than that outside the driers. 
Table (2): Daily average solar energy available (Q), air relative humidity (RH), air temperatures outside and inside the driers $\left(T_{a o}\right.$ and $\left.T_{a i}\right)$, grapes temperature $\left(T_{g}\right)$, initial and final moisture contents $\left(M_{i}\right.$ and $\left.M_{f}\right)$, and mass of water removed $\left(m_{w}\right)$, for the four driers during the experimental period.

\begin{tabular}{|l|c|c|c|c|}
\hline \multicolumn{1}{|c|}{ Parameter } & STGD 1 & STGD 2 & STGD 3 & OSDS \\
\hline Solar energy available $(\mathrm{Q}), \mathrm{kWh}$ & 9.698 & 9.698 & 9.948 & 13.728 \\
\hline Air relative humidity $(\mathrm{RH}), \%$ & 33.6 & 37.3 & 40.9 & 26.6 \\
\hline Air temperature inside $\left(\mathrm{T}_{\mathrm{ai}}\right),{ }^{\circ} \mathrm{C}$ & 53.5 & 44.1 & 41.0 & 31.6 \\
\hline Grapes temperature $\left(\mathrm{T}_{\mathrm{g}}\right),{ }^{\circ} \mathrm{C}$ & 47.3 & 41.5 & 39.5 & - \\
\hline Initial moisture content $\left(\mathrm{M}_{\mathrm{i}}\right), \% \mathrm{wb}$ & $\mathbf{8 0 . 1 4 7}$ & $\mathbf{7 9 . 5 6 7}$ & $\mathbf{7 9 . 5 4 3}$ & $\mathbf{7 7 . 0 8 3}$ \\
Clusters & 80.42 & 80.77 & 79.83 & 77.67 \\
Parts & 79.55 & 80.34 & 79.57 & 78.35 \\
Grains & 80.47 & 77.59 & 79.23 & 75.23 \\
\hline Final moisture content $\left(\mathrm{M}_{\mathrm{i}}\right), \% \mathrm{wb}:$ & $\mathbf{1 7 . 1 1 1}$ & $\mathbf{1 8 . 4 6 0}$ & $\mathbf{2 0 . 7 5 6}$ & $\mathbf{2 1 . 1 7 6}$ \\
Clusters & 18.084 & 20.225 & 22.249 & 24.285 \\
Parts & 17.846 & 19.325 & 20.928 & 21.027 \\
Grains & 15.402 & 15.841 & 19.090 & 18.217 \\
\hline Total drying time, $\mathrm{hr}$ & 61.0 & 61.0 & 71.0 & 96.0 \\
\hline Mass of water removed $\left(\mathrm{M}_{\mathrm{w}}\right), \mathrm{kg}$ & $\mathbf{2 5 . 0 9}$ & $\mathbf{2 4 . 7 5}$ & $\mathbf{2 4 . 4 8}$ & $\mathbf{2 3 . 4 1}$ \\
Clusters & 8.37 & 8.35 & 8.15 & 7.76 \\
Parts & 8.26 & 8.32 & 8.16 & 7.98 \\
Grains & 8.46 & 8.08 & 8.18 & 7.67 \\
\hline
\end{tabular}

The grape temperature is a measure of the level of heat energy acquired by the grapes. A part of this heat was transferred to the interior of the grapes, causing a rise in temperature and vapour pressure, and formation of water vapour, and the remaining amount was utilized in evaporation of the moisture from the surface of grapes. The moisture from the interior was transferred to the surface in order to be evaporated. In the initial stages, the moisture removal rate was rapid since the excess moisture on the surface of grapes presents a wet surface to the drying air. It was also observed that, the grain grapes temperature was higher than that of the parts grapes and clusters, due to the grains has a large surface area for solar radiation as compared with the other grapes. 


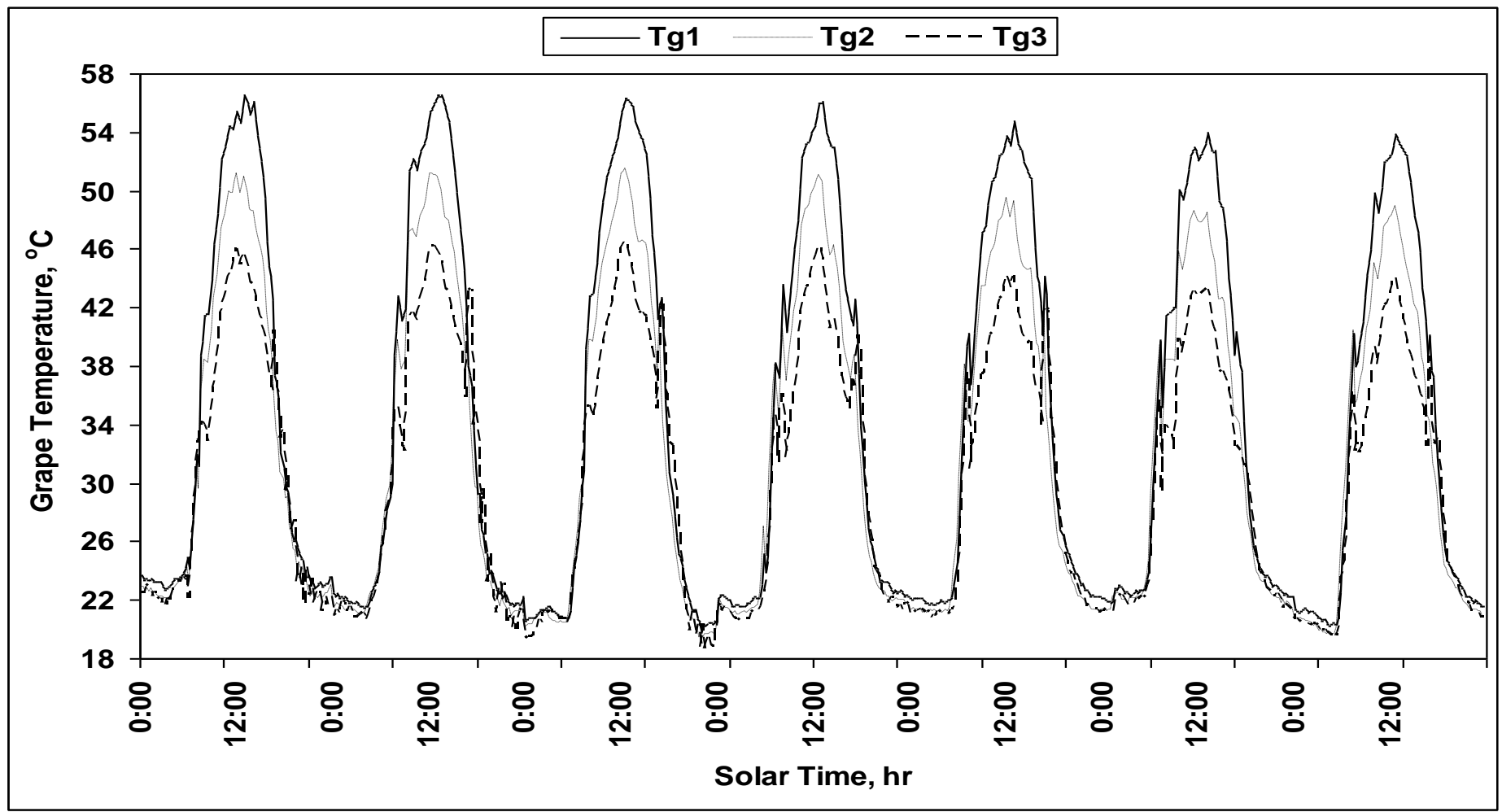

Fig. (4): Cyclic changes in grape temperatures for the three solar tunnel greenhouse driers during the experimental period. 
The grape temperatures measured inside the three solar tunnel greenhouse driers $\left(\mathrm{T}_{\mathrm{g}}\right)$ were used as a function of drying air temperatures $\left(\mathrm{T}_{\mathrm{ai}}\right)$ under specific conditions during the experimental period as shown in Fig. (5). Regression analysis showed a highly significant linear relationship ( $\mathrm{r}=$ $0.9977 ; \mathrm{P} \leq 0.001$ ) between these factors. The best fit equations relating the grape temperature to the drying air temperature were:-

$$
\begin{aligned}
& T_{g}\left(\text { STGD 1) }=0.9653\left(T_{a i}\right)\right. \\
& T_{\mathrm{g}}\left(\text { STGD 2) }=0.9647\left(\mathrm{~T}_{\mathrm{ai}}\right)\right. \\
& T_{g}\left(\text { STGD 3) }=0.9666\left(T_{a i}\right)\right.
\end{aligned}
$$
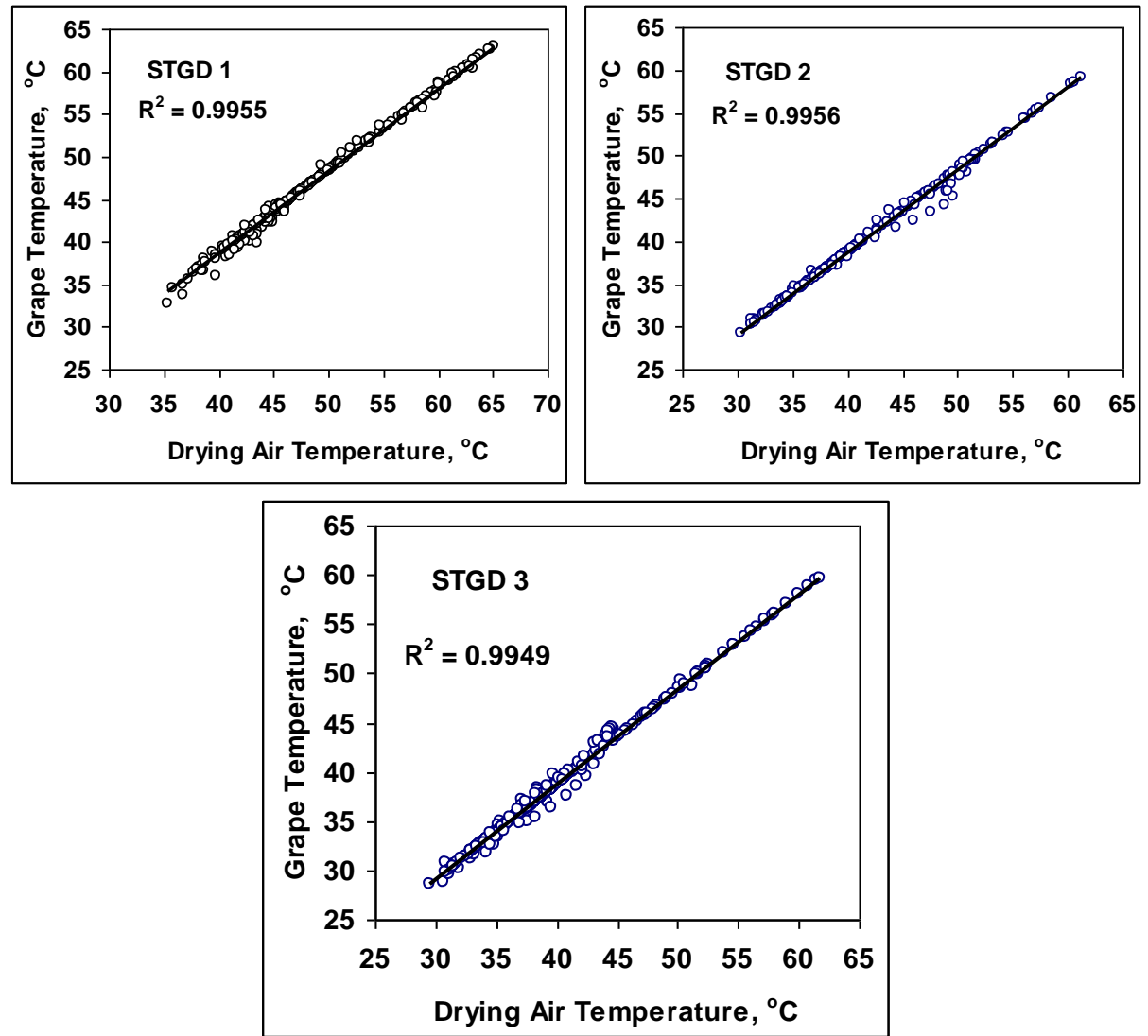

Fig. (5): Grapes temperature versus drying air temperature for the three solar tunnel greenhouse driers.

During the experimental period, the open sun drying method operated under meteorological parameters of; ambient air temperature ranged from 25.8 to $36.0^{\circ} \mathrm{C}$, air relative humidity ranged from $27.3 \%$ to $58.1 \%$, wind speed ranged from 1.1 to $11.3 \mathrm{~m} / \mathrm{s}$, and total solar radiation flux incident 
on horizontal surface ranged from 111.3 to $1015.4 \mathrm{~W} / \mathrm{m}^{2}$. During daylight the air relative humidity was gradually reduced, because the solar radiation became intense. At nighttime the air relative was rapidly raised. During the daylight the grapes temperature under the open sun drying system was higher than the surrounding air temperature. The maximum grapes temperature at and around noon reached about $42.7^{\circ} \mathrm{C}$. Heat was generated by the absorption of solar radiation by the grapes. The increased grapes temperature has the effect to evaporate the moisture content from the grapes. The role of the outside air was just to refresh the grapes. At nighttime the grapes temperature was fitted with the surrounding air temperature. It was also observed that, the grain grapes temperature was higher than that of the parts grapes and clusters, due to the grains has a large surface area for solar radiation as compared with the other grapes.

The initial moisture content, final moisture content, drying time, and drying rate for the four different solar drying methods (STGD1, STGD2, STGD3, and OSDS) and three different shapes of grapes (clusters, parts, and grains) during the experimental period were summarised and listed in Table (3). The initial moisture contents of the seedless grapes were appeared as $0.8015,0.7957,0.7954$, and 0.7708 gram of water per one gram of wet matter under four different methods of solar drying, respectively. The initial moisture contents during the experimental period were reduced to the final moisture contents of $0.1711,0.1846,0.2076$, and 0.2118 gram of water per one gram of wet matter under four different methods of solar drying and drying times, respectively as revealed in Table (3). This table also showed that the drying rate was affected by the shape of seedless grapes, moisture content, drying air temperature, and mass flow rate of drying air. There were differences in the final moisture contents of grapes shapes as grains, parts, and whole cluster. It can be observed that, the lowest value of final moisture content for the four different drying methods occurred in grains due to the grains had the largest surface area exposed to the solar radiation. Therefore it was absorbed a great amount of solar radiation which increased the grains temperature. This is in agreement with the data published by Sharma et al. (2009), when they reported that, the initial and final moisture contents must be ranged from $75-80 \%$ and $15-20 \%$,wb. The drying process helps 
in reducing the initial moisture content into a level below which deterioration does not occur and the product (raisins) can be stored for a definite period.

The actual drying time for the four different drying methods, respectively, was 61.0, 61.0, 71.0, and 96.0 hours as listed in Table (3). Consequently, STGD1 and STGD2 lowered the actual drying time by $14.08 \%$ and $36.46 \%$ as compared with STGD3 and OSDS, respectively. In general, solar driers enhance times in two ways. Firstly, the translucent or transparent, glazing materials over the collection area traps heat energy inside the solar drier, causing in raising the temperature of drying air. Secondly, the flexibility of enlarging the solar collection area allows for greater collection of the solar energy as occurred in shape of grapes.

The first solar drier (STGD1) was operated 7 days to reach the final moisture contents of $15.402,17.846$, and $18.084 \%$ wb for grains, parts, and clusters, respectively. The second solar drier (STGD2) was also operated 7 days to recognized the final moisture contents of 15.841, 19.325, and $20.225 \%$ wb for grains, parts, and clusters, respectively. While, the third one (STGD3) was run 8 days to reach the final moisture contents of $19.090,20.928$, and $22.249 \% \mathrm{wb}$ for grains, parts, and clusters, respectively. The open sun drying system (OSDS) has taken 11 days to approach the final moisture contents of 18.217, 21.027, and $24.285 \%$ wb for grains, parts, and clusters, respectively.

In the direct active solar drying using solar tunnel greenhouse driers, a part of incidence solar radiation on the polyethylene cover was reflected back to surrounding atmosphere and the remaining part was transmitted inside the solar drier. Further, a part of transmitted solar radiation is reflected back from the surface of the grapes. The remaining part was absorbed by the surface of the grapes. Because of the absorption of solar radiation, grapes temperature increased and emitted long wavelength radiation which was not allowed to escape to the atmosphere due to presence of polyethylene cover unlike open sun drying. Solar radiation passed through the polyethylene cover converted into low-grade heat when it struck an opaque surface (grapes surface). 
Table (3): Initial moisture content, final moisture content and actual drying time for the four different methods of solar drying and three different shapes of grapes during the experimental period

\begin{tabular}{|c|c|c|c|c|c|}
\hline Drier & $\begin{array}{c}\text { Shape of } \\
\text { Grapes }\end{array}$ & $\begin{array}{c}\text { Initial } \\
\text { moisture } \\
\text { content, \% } \\
\text { (w.b) }\end{array}$ & $\begin{array}{c}\text { Final } \\
\text { moisture } \\
\text { content, \% } \\
(\text { w.b) }\end{array}$ & $\begin{array}{c}\text { Actual } \\
\text { drying time, } \\
\text { hr }\end{array}$ & $\begin{array}{l}\text { Drying } \\
\text { rate, } \\
\mathrm{kg} / \mathrm{hr}\end{array}$ \\
\hline \multirow{4}{*}{ STGD 1} & Clusters & 80.42 & 18.084 & \multirow{4}{*}{61.0} & 0.1372 \\
\hline & Parts & 79.55 & 17.846 & & 0.1354 \\
\hline & Grains & 80.47 & 15.402 & & 0.1387 \\
\hline & Mean & 80.15 & 17.111 & & 0.1371 \\
\hline \multirow{4}{*}{ STGD 2} & Clusters & 80.77 & 20.225 & \multirow{4}{*}{61.0} & 0.1369 \\
\hline & Parts & 80.34 & 19.325 & & 0.1364 \\
\hline & Grains & 77.59 & 15.841 & & 0.1324 \\
\hline & Mean & 79.57 & 18.464 & & 0.1352 \\
\hline \multirow{4}{*}{ STGD 3} & Clusters & 79.83 & 22.249 & \multirow{4}{*}{71.0} & 0.1147 \\
\hline & Parts & 79.57 & 20.928 & & 0.1149 \\
\hline & Grains & 79.23 & 19.090 & & 0.1151 \\
\hline & Mean & 79.54 & 20.756 & & 0.1149 \\
\hline \multirow{4}{*}{ OSD } & Clusters & 777.67 & 24.285 & \multirow{4}{*}{96.0} & 0.0800 \\
\hline & Parts & 78.35 & 21.027 & & 0.0823 \\
\hline & Grains & 75.23 & 18.217 & & 0.0791 \\
\hline & Mean & 77.08 & 21.176 & & 0.0805 \\
\hline
\end{tabular}

This low-grade heat was then trapped inside the solar drier by what is known as the "greenhouse effect". Thus the temperature above the grapes inside the solar driers became higher. The polyethylene cover server one more purpose of reducing direct convective losses to the ambient which further became beneficial for rising drying air and grapes temperatures, respectively. However, convective and evaporative losses occurred inside the solar driers from the heated grapes. The moisture was taken away by the air entering into the solar driers by different mass flow rates from the top and leaving through another opening provided at the bottom of the drier. Whereas in open sun drying used solar energy, the short wavelength solar radiation fell on the grapes surface. A part of this energy was reflected back and the remaining part was absorbed by the surface depending upon the colour of grapes and the solar incident angle. The absorbed radiation was converted into thermal energy and consequence, the temperature of grapes increased. This resulting in long wavelength 
radiation lost from the surface of grapes to the surrounding air through moist air. In addition to long wavelength radiation loss there was convective heat loss too due to the blowing wind through moist air over the surface of grapes. Evaporation of moisture was taken place in the form of evaporative losses and so the grapes were dried.

The daily average drying rate for the four different drying methods during the experimental period was $0.1371,0.1352,0.1149$, and $0.0805 \mathrm{~kg} / \mathrm{hr}$, respectively. Consequently, the greatest value of drying rate was achieved under the STGD1, due to it had the highest temperature of drying air and lowest air relative humidity. Thus, the STGD1 enhanced and increased the drying rate by $1.41 \%, 19.32 \%$, and $70.31 \%$ as compared with the STGD2, STGD3, and OSDS, respectively. It was observed that, the drying of seedless grapes during the experimental period varied from hour to hour and day to another according to the moisture content of the grapes, drying air temperature, and intensity of solar radiation. The greatest values of drying rate for the four different solar driers $(0.2595,0.2449,0.2186$, and $0.1893 \mathrm{~kg} / \mathrm{hr}$, respectively) were achieved during the first three days of the drying process which represented $75.21 \%, 74.63 \%, 71.33 \%$, and $60.27 \%$, respectively, of the total drying rate, due to the high moisture content of the grapes at that days. It was also observed that the drying rate of the three solar tunnel greenhouse driers was higher than that the open sun driers as it operated under the natural climatic conditions of solar radiation intensity, ambient air temperature and relative humidity.

It was observed that, there were differences in the final moisture contents and drying rates of grapes shapes as grains, parts, and whole cluster. The lowest final moisture content and greatest drying rate for the four solar driers was achieved by grains as compared with parts and whole clusters due to the great amount of short wavelength solar radiation absorbed by the largest surface area of grains. A part of absorbed thermal energy was conducted into the interior of the grapes. This causing in a rise in temperature and formation water vapour inside the grapes and then diffused towards the surface of the grapes and finally lost thermal energy in the grapes and then diffused towards the surface of the grapes and finally lost the thermal energy in the form of evaporation. 
In the first stage of drying process, the moisture removal was rapid since the excess moisture on the surface of the grapes presented a wet surface to the drying air. Therefore, the grapes grains in active and passive drying systems during the experimental period dried faster than parts and cluster as shown in Fig. (6). A fairly good agreement between measured and calculated drying curves of grapes shapes has been achieved. Therefore, it can be concluded that the proposed empirical correlations for the drying constant (k) could be satisfactorily describing the experimental drying curves of the seedless grapes. This is in agreement with the data published by Bauman et al. (2005) and Kassem (2007).

The data obtained experimentally were functioned for determination the drying coefficient $(\mathrm{K})$ of various grapes shapes (grains, parts, and clusters) using the simple exponential equation. The moisture ratio (MR) and the drying time $(\mathrm{t})$ were used to obtain the drying coefficient $(\mathrm{k})$ for the three different grapes shapes according to El-Sahrigi, et al., 2007. The exponential equation for the best fit was in the form of:

$$
\operatorname{MR}=\left(\mathrm{M} / \mathrm{M}_{0}\right) \quad=\exp (-\mathrm{kt})
$$

The computed values of the drying coefficient $(\mathrm{K})$ for the three active solar driers and three different grapes shapes are listed in Table (4). It was observed that, the drying coefficient for the three various grapes shapes decreased as the drying air temperature and air relative humidity decreased. Therefore, the effect of drying air temperature $\left(\mathrm{T}_{\mathrm{ai}}\right)$ on the drying coefficient $(\mathrm{k})$ for the three different grapes shapes during the experimental period was examined using simple regression analysis.

The regression analysis showed a highly significant linear relationship between these parameters $(r=0.8961 ; P \leq 0.001)$. The regression equations for the best fit were:

$\begin{array}{lll}k(\text { grains }) & =0.0084+0.0008\left(T_{a i}\right) & \mathbf{R}^{2}=0.7449 \\ k(\text { parts }) & =0.0063+0.0009\left(T_{a i}\right) & \mathbf{R}^{2}=0.8537 \\ k \text { clusters }) & =0.0080+0.0008\left(T_{a i}\right) & \mathbf{R}^{2}=0.8102\end{array}$



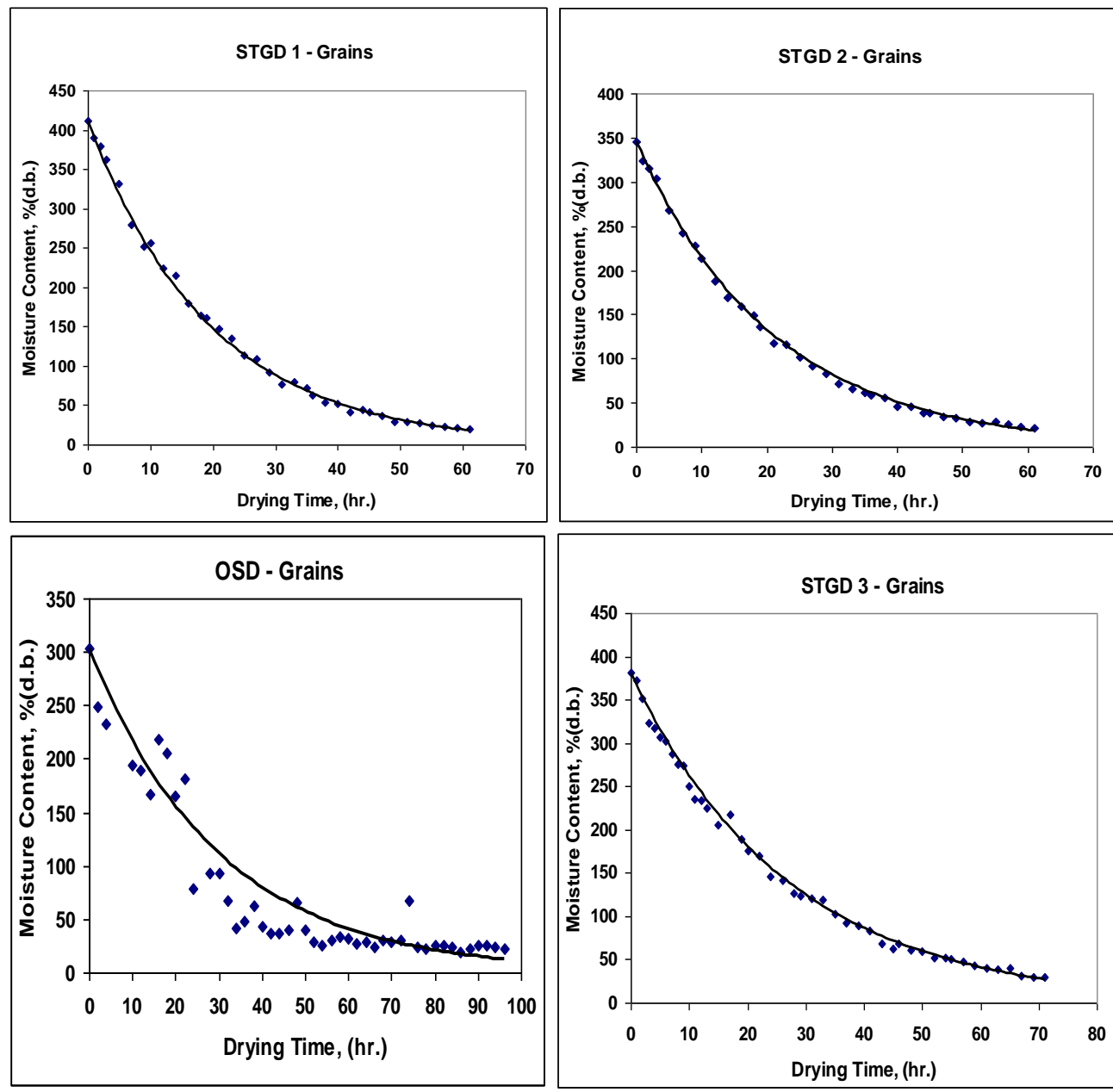

Fig. (6): Variation of moisture content during drying time of grapes grains for the four solar driers.

Table (4): daily average drying coefficient for the three various grapes shape during the experimental period.

\begin{tabular}{|c|c|c|c|c|c|}
\hline & Drying air & Air relative & \multicolumn{3}{|c|}{ Drying coefficient (k), 1/hr } \\
\cline { 4 - 6 } Drier & temperature, ${ }^{\circ} \mathrm{C}$ & humidity, $\%$ & Grains & Parts & Clusters \\
\hline STGD1 & 49.9 & 33.6 & 0.0529 & 0.0519 & 0.0508 \\
\hline STGD2 & 45.5 & 37.3 & 0.0505 & 0.0499 & 0.0485 \\
\hline STGD3 & 40.1 & 40.9 & 0.0405 & 0.0398 & 0.0392 \\
\hline
\end{tabular}

Similar regression analysis was executed to test the effect of average air relative humidity $(\mathrm{RH})$ on the drying coefficient $(\mathrm{k})$ for the three different grapes shape. The regression analysis revealed a highly significant linear 
relationship between these parameters $(\mathrm{r}=0.9819 ; \mathrm{P} \leq 0.001)$. The regression equations for the best fit were:

$$
\begin{array}{lll}
\mathbf{k}(\text { grains }) & =0.1108+0.00175(\mathbf{R H}) & \mathbf{R}^{2}=0.9367 \\
\mathbf{k}(\text { parts }) & =0.1079+0.00170(\mathbf{R H}) & \mathbf{R}^{2}=\mathbf{0 . 9 8 6 3} \\
\mathbf{k} \text { (clusters) } & =0.1047+0.00160(\mathbf{R H}) & \mathbf{R}^{2}=\mathbf{0 . 9 6 9 5}
\end{array}
$$

It was also observed that, the shapes of seedless grapes has effect on the drying coefficient because they affect greatly on drying rate at the falling period and that related with the drying constants. The drying constant $(\mathrm{k})$ of grapes grains was higher as compared with grapes parts and clusters. These results related to drying rate with drying time which they have effect on the drying constant.

The simple exponential equation described the experimental data of solar drying behaviour of seedless for the various grapes moisture ratios showed a highly significant relationship between observed and predicted moisture ratios as shown in Fig. (7). There was no apparent bias in the prediction by the suggested model (simple exponential equation). This simple model gave a satisfactorily drying behaviour as the values of coefficient of determination are greater than 0.99 and the standard error is not greater than 0.0175

One of the objectives of the present study was also to determine the effect of four different drying systems on total heat energy utilised in drying process and total heat energy lost from the driers. The drying process is basically a simultaneous heat and mass transfer. As the solar radiation is transmitted inside the solar drier, a part of this radiation can be used in two ways: either heating up the drying air inside the solar drier or heating up the wet grapes directly through absorption of solar radiation by the wet grapes depending upon the colour of the grapes. Due to the absorption of solar radiation, grapes temperature increased and consequence emitting long wavelength radiation which cannot pass back the cover. Thus the air temperature above the grapes inside the solar drier became higher. The remaining part is lost through conductive, convective and radiative from the heated air and grapes inside the solar drier. The term "thermal energy utilised for drying" includes the following: sensible heat used to raise the temperature of the wet grapes, sensible heat used to raise the temperature of the water in the wet grapes, and latent heat used to vaporise the water in the wet grapes. 

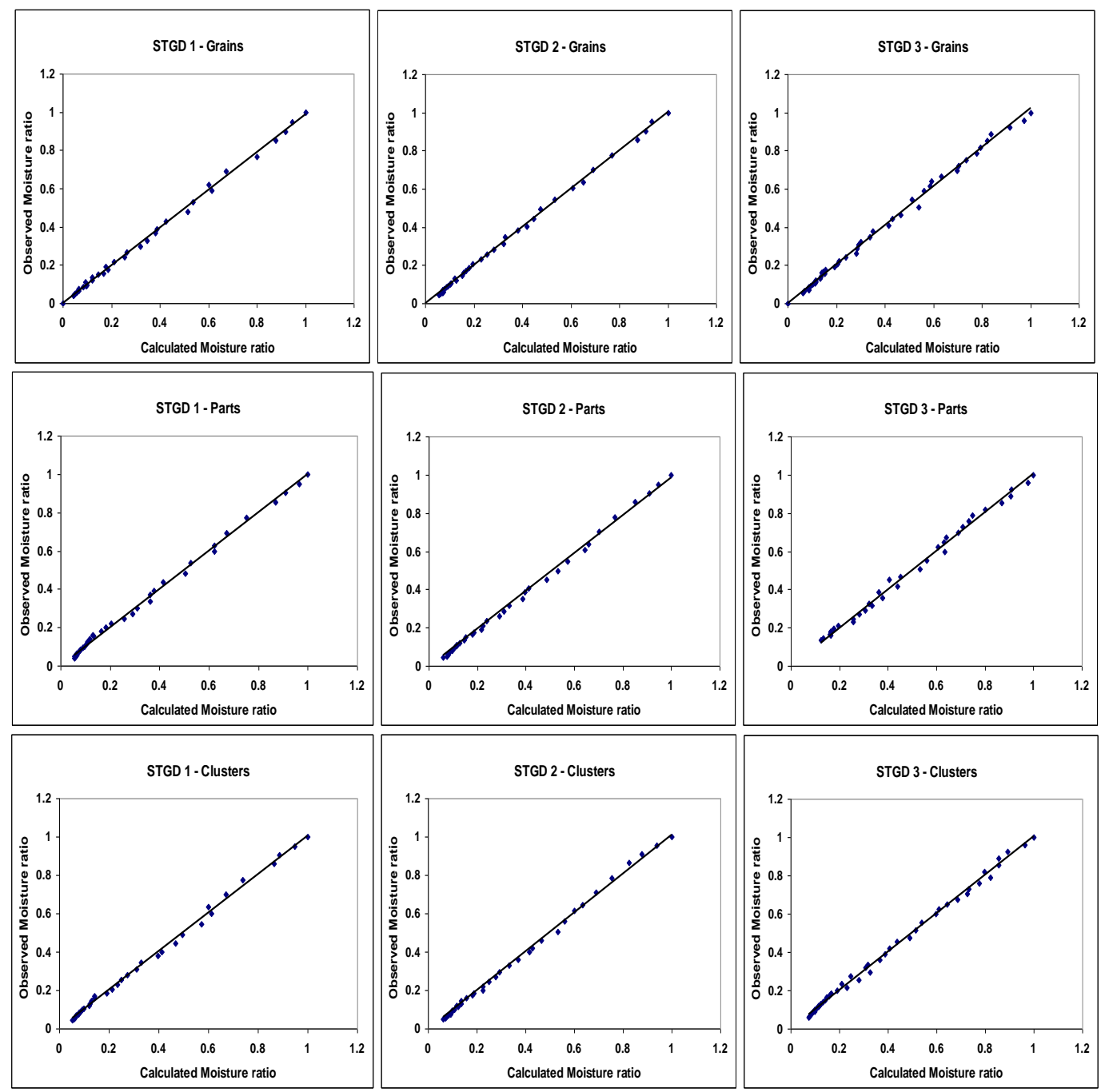

Fig. (7): observed moisture ratios versus predicted for the three active solar driers and three various grapes shape.

The thermal efficiencies of different types of solar driers have been computed from the data obtained from the experimental tests using equation (3.18). The computed data of the solar drying efficiency based on thermal energy utilisation against thermal energy available for the four different drying modes are given Tables (4.7, 4.8, and 4.9). The maximum value of thermal efficiency (42.49\%) was achieved in STGD1 during the first day of drying process due to lower mass flow rate of air, higher 
drying air temperature, and higher moisture content of grapes. This value gradually decreased until reached the minimum value at the end of the drying process due to rapid reduction in moisture content of grapes. The daily average thermal efficiencies for the four different solar drying modes, respectively, were $22.37 \%, 21.57 \%, 19.12 \%$, 1and $10.81 \%$. Consequently, STGD1 increased the thermal efficiency by $3.38 \%, 18.31 \%$, and $109.25 \%$ as compared with STGD2, STGD3, and OSDS, respectively. These differences in thermal efficiencies might have caused by the differences in mass flow rate of drying air, drying air temperature, and drying time rather than the initial moisture content. It was observed that there was no significant difference in the value of thermal efficiency with solar tunnel greenhouse driers. This might be due to active solar drying modes were sufficient enough for the movement of moisture. It could mean that the amount of solar energy available was adequate but not fully utilised. Whereas, the difference between any solar tunnel greenhouse drier and the open sun drier was highly significant. The thermal efficiency of different solar drying modes was affected by the properties of seedless grapes (e.g. moisture content, and shape of grapes) and ambient conditions (e.g. solar radiation intensity, temperature, relative humidity, and wind speed).

The arithmetical model of heat energy balance that was marked out before revealed that, there are many parameters affecting energy balance on the solar tunnel greenhouse driers. These parameters and their influence on thermal energy balance are as; solar energy available inside the solar drier, useful heat gain, heat energy utilised in drying process and heat energy losses. The computed data of the arithmetical model showed that, the difference between input heat energy (measured solar energy available inside) and output heat energy (calculated useful heat gain, heat energy utilised in drying process, and heat energy losses) the accumulated heat energy inside the solar drier. It was also revealed that, the ratio of output heat energy to the input heat energy presented the validation of heat energy balance model. The validation of the mathematical model which described the relationship between the output and input heat energies for the three solar driers (STGD1, STGD2, and STGD3) was 95.60\%, 96.05\%, 

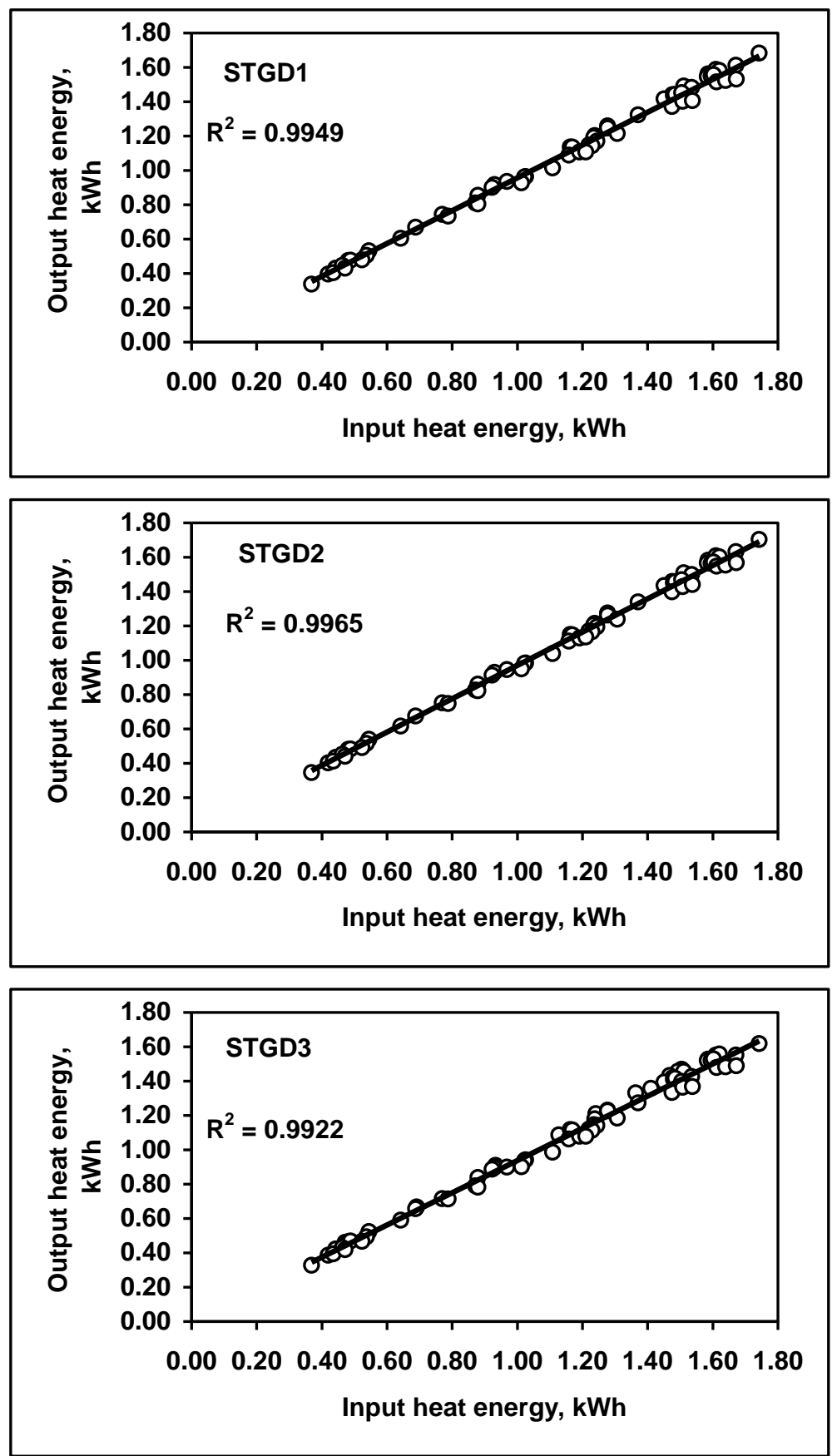

Fig. (8): Output heat energy against input heat energy for the STGD1, STGD2, and STGD3 during the experimental period 
and $97.80 \%$, consequently, about $4.40 \%, 3.95 \%$, and $2.20 \%$ of the total heat energy input was accumulated, respectively.

To assess and examine the best model which may be used to correlate the hourly average measured solar energy available with the hourly average output heat energy (sum of useful heat gain, heat energy utilised in drying process, and heat energy losses), all the obtained data for the three solar driers (STGD1, STGD2, and STGD3) were functioned in regression analysis as shown in Fig. (8). Regression analysis revealed a highly significant linear relationship $(\mathrm{R}(\mathrm{STGD} 1=0.997, \mathrm{R}(\mathrm{STGD} 2)=0.998$, and $\mathrm{R}(\mathrm{STGD} 3)=0.996 ; \mathrm{P} \leq 0.001)$ between these parameters. The regression equations for the best fit were:

$$
\begin{array}{ll}
Q_{\text {output }}(\text { STGD1 }) & =0.955968\left(Q_{\text {input }}\right) \\
Q_{\text {output }}(\text { STGD2 }) & =0.960467\left(Q_{\text {input }}\right) \\
Q_{\text {output }}(\text { STGD3 }) & =0.977980\left(Q_{\text {input }}\right)
\end{array}
$$

\section{REFERENCES}

Abdellatif, S. M. ; and Helmy, M. A. (1993) "Solar dryers utilization in clover drying for providing forage materials in critical feed period" J. Agric. Sci. Mansoura University, 18(8):2375-2383.

AOAC (1995) "Official methods of analysis of the association of official analytical chemists". 14th Ed. Published by the Association of Official Analytical Chemists, Arlington, Virginia, 22209 USA.

Ayensu, A. (1997) "Dehydration of food crops using a solar dryer with convective heat flow" J. of Solar energy, 59(4-6):121-126.

Bargach, M. N. ; Tadili, R. ; Dahman, A. S. ; and Boukallouch, M. (2000) "Survey of thermal performances of a solar system used used for heating of agricultural greenhouses in Morocco, Renewable Energy, 20:415-433.

Condori, M. ; and Luis, S. (1998) "The performance of forced convection greenhouse driers" Renewable Energy, 13(4):453-469.

Condori, M. ; Echazu, R. ; and Saravia, L. (2001) "Solar drying of sweet pepper and garlic using the tunnel greenhouse drier" Renewable Energy, 22(4):447-460. 
Dickerson, R. W., Jr. (1969). Thermal properties of foods. In "The freezing preservation of foods" 4th ed, vol.2 (D.K. Tressler, W.B Van Arsdel, and M.J. Copley, eds.) pp.26-51 AVI Publ.co. Westport, Connecticut, cited by Singh, R. P. and Heldman, D. R. (1993)

Duffie, J. A. ; and Beckman, W. A. (1991) "Solar engineering of thermal processes" John Wiley and Sons, New York, USA.

El-Ghetany, H. H. (2006) "Experimental investigation and empirical correlations of thin layer drying characteristics of seedless grapes" Energy Conservation and Management, 47:610-1620.

El-Sahrigi, A. F. ; Matouk, A. M. ; Abdellatif, S. M. and Awad, A. S. (2007) "Development and evaluation of a portable grapes dryer" Egypt Journal Agriculture Research, 85(1).

El-Sebaii, A. A. ; Aboul-Enein, S. ; Ramadan, M. R. I. ; and ElGohary, H. G. (2002a) "Experimental investigation of an indirect type natural convective solar dryer" Energy Conservation and Management, 43:2251-2266.

El-Sebaii, A. A. ; Aboul-Enein, S. ; Ramadan, M. R. I. ; and ElGohary, H. G. (2002b) "Empirical correlations for drying kinetics of some fruits and vegetables" Energy, 27(9):845-859.

Ibrahim, H. I. K. (1990) "Solar energy dehydration of fruits and vegetables and its effects on the enzymatic activities of the process" Unpublished, M.Sc. Thesis, Departement of food Sci., Dep., Fac. Of Agri., Ain Shams Univ. Egypt.

Jayaraman, K. S. ; and Gupta, D. K. (1995) "Hand book of industrial drying" Marul Dekker Inc.

Kumar, A. ; and Tiwari, G. N. (2006) "effect of shape and size on convective mass transfer coefficient during greenhouse drying (GHD) of Jaggery" J. of Food Engineering, 73:121-134.

Kumar, A. ; and Tiwari, G. N. (2007) "Effect of mass on convective mass transfer coefficient during open sun and greenhouse drying of onion flakes" J. of Food Engineering, 79:1337-1350. 
Matteo, M. D. Luciano, C. L. ; Galiero, G. ; and Crescitelli, S. J. (2000) "Thin layer drying models of grapes" J. of Food Engineering, 46:83-89.

Pangavhane, D. R. ; Sawhney, R. L. ; and Sarsavadia, P. N. (1999) effect of various dipping pretreatment on drying kinetics of Thompson seedless grapes" J. of Food Engineering, 39(2):211-216.

Timoumi, S. ; Mihoubi, D. ; and Zagrouba (2004) "Simulation model for a solar drying process" Desalination, 168:111-115.

Tiwari, G. N. (2003) "Greenhouse technology for controlled environment" New Delhi: Narosa Publishing House.

Tiwari, G. N. ; Bhatia, P. S. ; Singh, A. K. ; and Goyal, R. K. (1997) "Energy balance equation for the drying product" Energy Conservation and Management, 38:751-759.

Yaldiz, O. ; Ertekin, C. ; and Uzun, H. I. (2001) "Investiagtion of a thin layer solar drying of sultana grapes" Energy, 26:457-465.

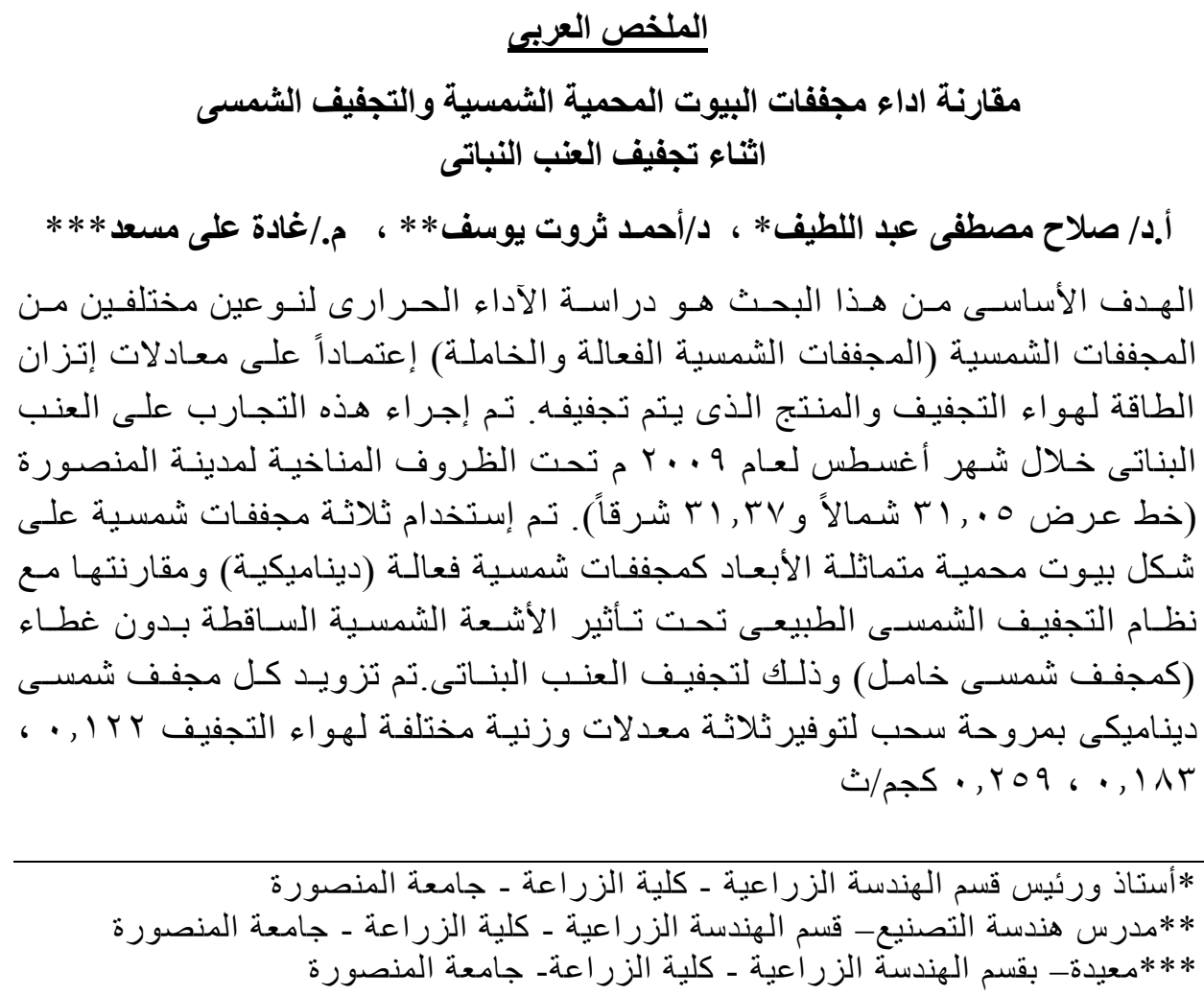




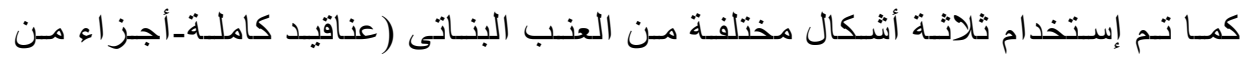

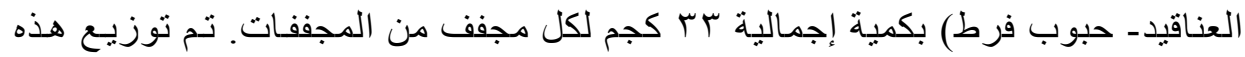

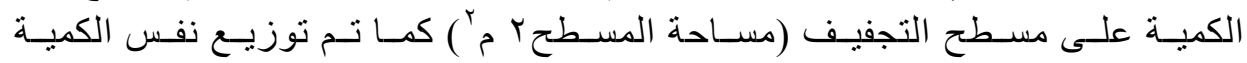

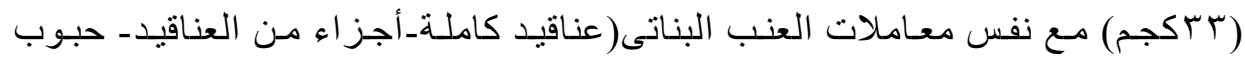

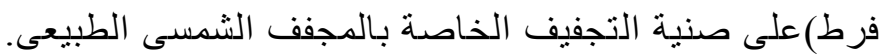

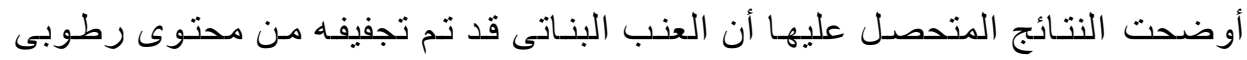

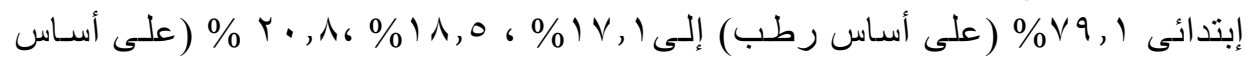

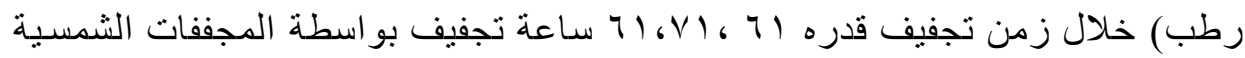

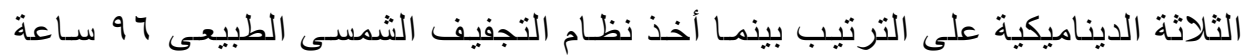

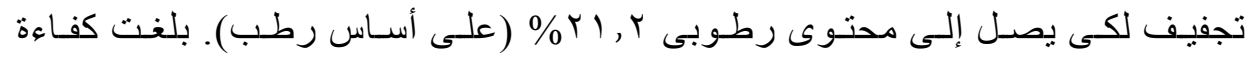

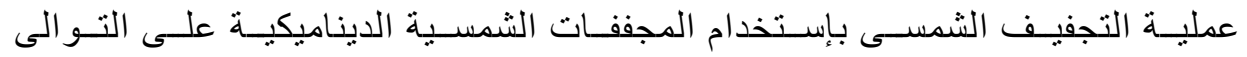
ا

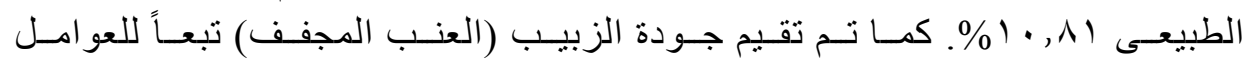

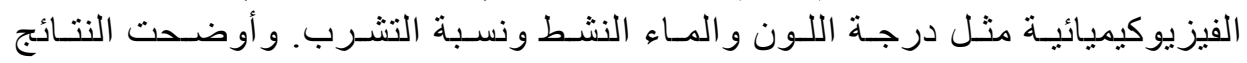

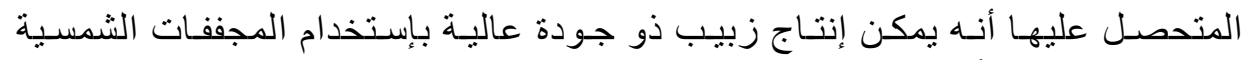

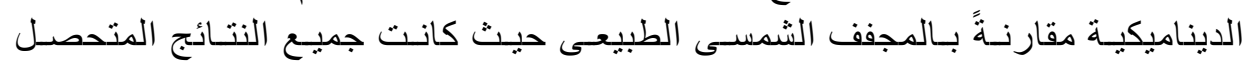
عليها مرضية. 